Textures and Microstructures, 1988, Vols. 8 \& 9, pp. 693-716

Reprints available directly from the publisher

Photocopying permitted by license only

(C) 1988 Gordon and Breach Science Publishers Inc.

Printed in the United Kingdom

\title{
The Evaluation of the
}

Distribution of Residual

Stresses of the I. Kind (RSI) and of the II. Kind (RS II) in Textured Materials

\author{
V. HAUK and H.-J. NIKOLIN \\ Institut für Werkstoffkunde, Rheinisch-Westfälische Technische Hochschule \\ Aachen, D-5100 Aachen, FRG
}

(Received 31 July, 1987; in final form 23 January, 1988)

\section{Dedicated to the memory of Professor Günter Wassermann}

Recommendations are given for the type and quantity of X-ray measurements of interplanar spacings on different peaks required to evaluate the residual stress (RS) state within materials having strongly preferred orientations as a result of cold rolling. The variation of RS I and of RS II with depth from the surface can be determined by measuring on new surfaces obtained by etching several layers from both sides of the specimens and by measuring small thin specimens taken from different parts of the cross-section. Additional measurements by the etchingdeflection method show the variation of RS I. Here RS II is understood as the mean value of the stresses of those crystallites which contribute to the measurement after subtraction of RSI. The results obtained on a cold rolled thin steel strip show variation with depth of RS II only.

KEY WORDS: Residual stresses, ODF analysis, $\sin ^{2} \psi$ law, cold rolled steel.

\section{INTRODUCTION}

The principle of X-ray stress evaluation (XSE) is based on the measurement of interplanar spacings $\mathrm{D}_{\{h k l\}}$ of a particular set of 


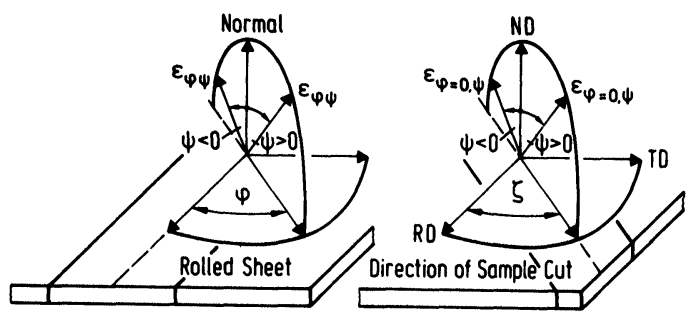

Figure 1 Definition of angles and directions.

planes as a function of the angle $\psi$ between the normals of the lattice plane and the surface of the specimen (Hauk and Macherauch, 1982 and 1984; Hauk, 1987a). Figure 1 shows the parameters which characterize the measuring directions i.e., angle $\psi$, azimuth $\varphi$, rolling direction (RD), transverse direction (TD), normal direction (ND) and the angle $\xi$ of the specimen cut. The residual stresses (RS) which are inherent in the material are divided into RS I (macro-RS) and RS II + III (micro-RS) as stated by Macherauch et al. (1973), Wolfstieg and Macherauch (1976) and Kloos (1979). Parts of the micro-RS are sometimes called deformation-RS due to their origin (Hauk, 1982b). Figure 2 makes clear the definition of the RS in case of a two phase material and shows the formulae for the compensation of the RS over the cross-section of the specimen and within the phases. The fact that only a part of crystallites of one phase contribute to the interference line is taken into consideration by the introduction of the averaged values $\langle\sigma\rangle$ in the XSE. In the following we understand RS II always as the X-ray mean value of the stresses of those crystallites which contribute to the measurement after subtraction of RSI. Whether this mean value is to understand generally as the mean value of the phase or as the mean value of some especially oriented crystallites is depending on the kind of measurement and evaluation (see also Hauk, 1955).

As many material states are fine grained and have statistically distributed crystallites lattice spacing/strain vs. $\sin ^{2} \psi$ dependencies are linear. The RS are evaluated from these slopes using the X-ray elastic constants (XEC) which take into account the elastic ani- 


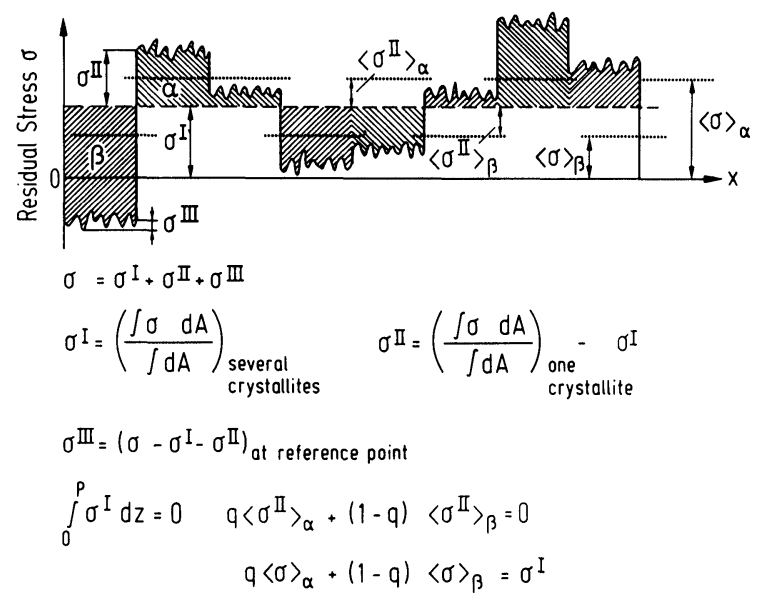

Figure 2 Illustration of RS I, II, III in the case of a two phase material schematically, formulae for compensation; $P$ cross-section of the specimen; $q$, $(1-q)$ volume percentage of the phases; $\langle\sigma\rangle$ X-ray mean values.

sotropy of the crystals (Hauk, 1982a and 1987a; Hauk and Macherauch, 1982 and 1984). Materials having preferred orientations are characterized by the orientation distribution function (ODF) (Bunge, 1965, Roe 1965) which shows the distribution of crystallites with preferred orientations. They can mostly be described approximately by ideal orientations (Wassermann and Grewen, 1962). Due to the elastic and plastic anisotropy resulting from texture, in most cases non-linear $\mathrm{D}_{\{h k l\}}$ vs. $\sin ^{2} \psi$ distributions are observed with textured materials. In these cases the usual XSE can not be employed.

\section{POSSIBILITIES OF THE XSE IN THE CASE OF TEXTURED MATERIALS}

The different models of calculation considering the texture if RS I or load stresses are present are shown in Table 1 (authors are mentioned in the Table). In all these papers the elastic behaviour of a single crystal was employed using the results of Glocker (1938), 


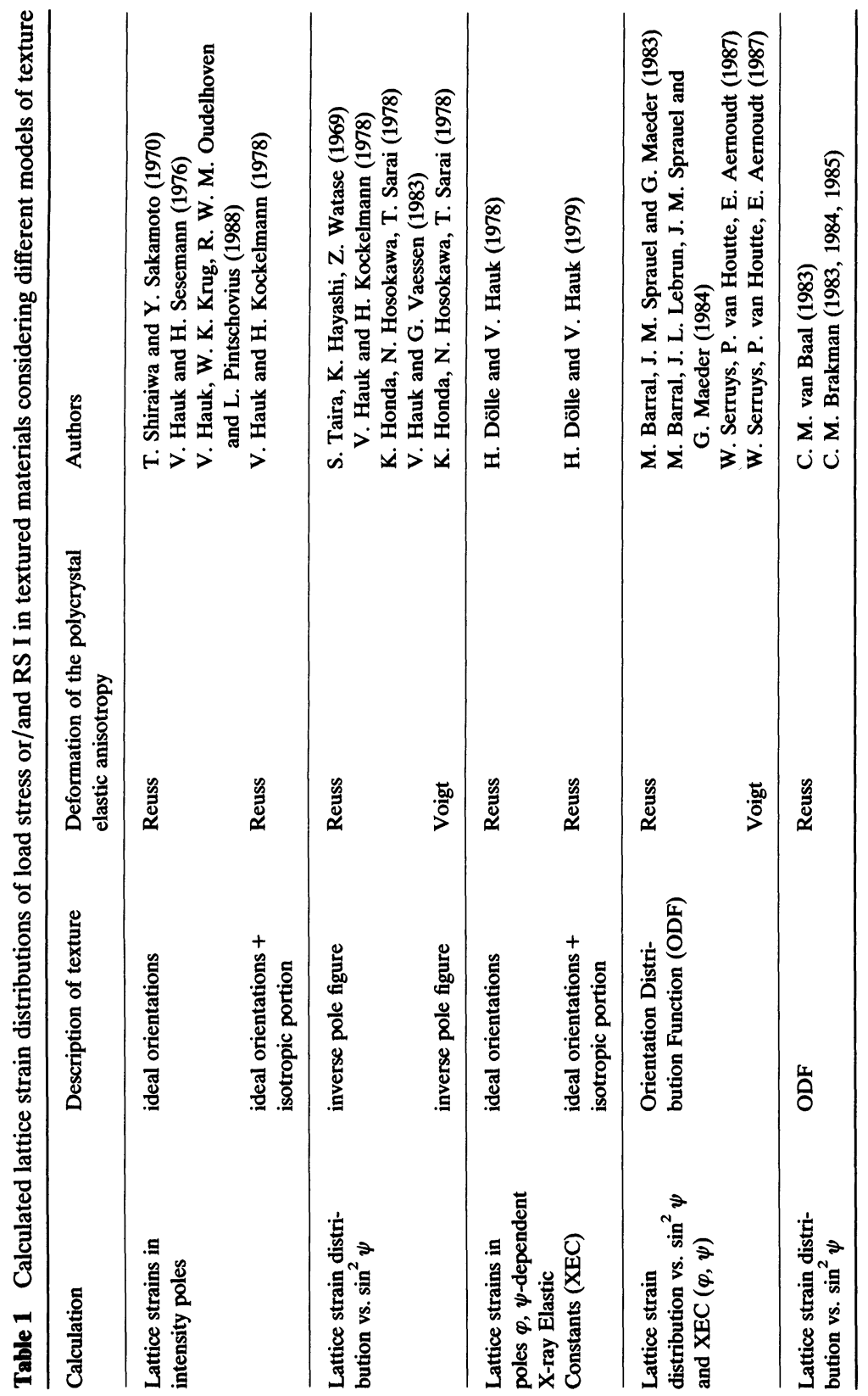


Schiebold (1938), Möller and Martin (1939). To describe the deformation of polycrystals in most cases the approximation of Reuss (1929), homogeneous stress, and sometimes the approximation of Voigt (1928), homogeneous strain, or a combination of both are used. The texture is described by ideal orientations, sometimes taking into account the isotropic parts or by inverse polefigures or by the ODF. In general all components have RS which are often a combination of RS I + II and especially in textured materials different oriented crystallite groups may have different RS II. Therefore these models for evaluating RS which can not take into account RS II often lead to false results.

A different way of XSE on materials having preferred orientations was introduced by Hauk et al., (1975) who proposed the use of multiple reflections with high indices, involving more than one set of planes when measuring steels. The result of measurements using $\{732+651\}$-reflections of ferrite with Mo-radiation showed linear D vs. $\sin ^{2} \psi$ dependencies which enabled the usual XSE. Recent results (Hauk and Vaessen, 1983 and Hauk et al., 1985) confirmed the procedure on a broad basis. Furthermore calculations (Hauk and Vaessen, 1983) demonstrate that investigations on the $\{732+$ $651\}$-peaks will have linear D vs. $\sin ^{2} \psi$ distributions in the range $0 \leqq \sin ^{2} \psi \leqq 0.5$ if the texture, the elastic anisotropy of the singlecrystals and RS I are taken into consideration. The reasons for this are the relative large penetration depth of the Mo-radiation and especially the high multiplicity-factor of these planes so that many differently oriented crystallite groups with commonly different RS II contribute to the mean lattice strain. It should be remembered that the result may consist of RS I and RS II also using the Mo-radiation and measuring on $\{732+651\}$-peaks.

Another recently used possibility which has proved valuable is the method of measuring the lattice strain in especially oriented groups of crystallites. This method of XSE on textured materials was applied to wires (Willemse et al., 1982 and Willemse and Naughthon, 1985) to cold rolled steels (Hauk and Vaessen, 1985; Hauk et al., 1985; Pintschovius et al., 1987 and Feja et al., 1987) to cold rolled nickel, aluminium- and copper-materials (Baron et al., 1987 and Hauk and Oudelhoven, 1988) and to layers having electrolytefiber-textures (Baron and Hauk, 1988). Calculations on cold rolled steels can be found in (Hauk et al., 1988). 


$$
\varepsilon_{\mathrm{hkl}}=\sum_{i=1}^{3}\left[s_{12}+s_{0}\left(\alpha^{2} \alpha_{i}^{2}+\beta^{2} \beta_{i}^{2}+\gamma^{2} \gamma_{i}^{2}\right)+\frac{1}{2} s_{44}\left(\alpha \alpha_{i}+\beta \beta_{i}+\gamma \gamma_{i}\right)^{2}\right] \sigma_{i}
$$

Figure 3 The strain formula of single crystals (Glocker, 1938; Schiebold 1938; Möller and Martin 1939).

The conditions under which this last method may be used are as follows: The texture can be described by ideal orientations, the strain state of the crystal groups with preferred orientations must be known very precisely, the measurement of the absolute lattice spacings must be done exactly on many planes, the different oriented crystallite groups are considered as being single crystals. The planes which can be measured in RD and TD for each crystallite group belong to a common zone respectively. The $\psi$-angles under which the measurements should be done are those where intensity poles of the appropriate ideal orientation occur. To evaluate the RS the D-values are used at these $\psi$-angles and the calculation is done by the single-crystal-equation (Glocker, 1938; Schiebold, 1938; Möller and Martin, 1939), Figure 3. Figure 4 (Hauk, 1986) includes the equations in the case of principal stresses $\sigma_{1}, \sigma_{2}, \sigma_{3}$ in the specimen system given by RD, TD, ND of these five important ideal orientations which are necessary to describe the textures of iron, nickel, copper and brass. In most cases measurements in the RD and TD at the poles of the appropriate crystallite groups are sufficient. The evaluation of the RS state can be improved using all poles of the ideal orientation and taking into account the quasi-isotropic part. Strain polefigures require a greater effort even if they are worked out automatically and contain much more information than needed simply to evaluate RS.

\section{EVALUATION OF THE DISTRIBUTION OF THE RSI AND RS II OVER THE CROSS-SECTIÓN}

The separation of the RS I + II is possible when measuring on two or multiple phase materials having sufficient volumes in all phases so that X-ray measurements are possible with necessary accuracy. 


\begin{tabular}{|c|c|c|c|c|}
\hline $\begin{array}{l}\text { Ideal } \\
\text { orientation }\end{array}$ & $\varepsilon_{\varphi=0, \psi}$ & $\begin{array}{l}\text { Zone- } \\
\text { oxis }\end{array}$ & $\begin{array}{l}\text { Phase } \\
\text { solid } \\
\text { solution }\end{array}$ & $\{h k \mid\}$ \\
\hline \multirow{2}{*}{211}$\langle 01 \overline{1}\rangle$ & \multirow{4}{*}{$\begin{array}{l}\left(s_{12}+\frac{1}{6} s_{0}\right) \sigma_{1}+\left(s_{12}+\frac{1}{3} s_{0}\right) \sigma_{2}+\left(s_{12}+\frac{1}{2} s_{44}+\frac{1}{2} s_{0}\right) \sigma_{3} \\
+\frac{1}{2}\left[\left(s_{44}+\frac{2}{3} s_{0}\right) \sigma_{1}-\left(\frac{2}{3} s_{0}+s_{44}\right) \sigma_{3}\right] \sin ^{2} \Psi\end{array}$} & \multirow[t]{2}{*}[\begin{array}{lll}{1}&{1}&{11}\end{array}]{} & $\mathrm{Fe}$ & $\begin{array}{l}\{110\}\{211\}\{220\} \\
(541)\{642\}\end{array}$ \\
\hline & & & Cu $2 n$ & $\mid 211\}$ \\
\hline \multirow{2}{*}{011}$\langle 21 \overline{1}\rangle$ & & \multirow{2}{*}{ [1 } & Cu & \multirow{2}{*}{$(220)(844)$} \\
\hline & & & $\mathrm{Ni}$ & \\
\hline$\{111\rangle\langle 2 i \overline{1}\rangle$ & $\begin{array}{l}\left(s_{12}+\frac{1}{3} s_{0}\right) \sigma_{1}+\left(s_{12}+\frac{1}{3} s_{0}\right) \sigma_{2}+\left(s_{12}+\frac{1}{2} s_{44}+\frac{1}{3} s_{0}\right) \sigma_{3} \\
+\frac{1}{6}\left[\left(3 s_{44}+s_{0}\right) \sigma_{1}-s_{0} \sigma_{2}-3 s_{44} \sigma_{3}\right] \sin ^{2} \Psi \\
+\frac{1}{6} \sqrt{2} s_{0}\left(\sigma_{1}-\sigma_{2}\right) \sin 2 \Psi\end{array}$ & [011] & $\mathrm{Fe}$ & $\begin{array}{l}\{110\}\{200\}\{211\} \\
(220\}\{222\}\end{array}$ \\
\hline$\{100 \mid\langle 011\rangle$ & $\begin{array}{l}s_{12} \sigma_{1} \cdot s_{12} \sigma_{2}+s_{11} \sigma_{3} \\
+\frac{1}{2}\left[\left(s_{44} \cdot s_{0}\right) \sigma_{1} \cdot s_{0} \sigma_{2}-\left(2 s_{0}+s_{46}\right) \sigma_{3}\right] \sin ^{2} \Psi\end{array}$ & $10 \div 11$ & $\mathrm{Fe}$ & $\begin{array}{l}\{110\}\{200\}\{211\} \\
\{222\}\end{array}$ \\
\hline \multirow{2}{*}{211}$\langle\overline{1} 111\rangle$ & $\left(s_{12}+\frac{1}{3} s_{0}\right) \sigma_{1}+\left(s_{12}+\frac{1}{6} s_{0}\right) \sigma_{2}+\left(s_{12}+\frac{1}{2} s_{14}+\frac{1}{2} s_{0}\right) \sigma_{3}$ & \multirow{2}{*}[\begin{array}{lll}{0}&{11}\end{array}]{} & $\mathrm{Ni}$ & \multirow{2}{*}{$\begin{array}{l}\{220\}\{311\}\{222\} \\
\{331\}\end{array}$} \\
\hline & $+\frac{1}{6} \sqrt{2} s_{0}\left(\sigma_{2}-\sigma_{3}\right) \sin 2 \psi$ & & Cu & \\
\hline
\end{tabular}

\begin{tabular}{|c|c|c|c|c|}
\hline $\begin{array}{l}\text { Ideal } \\
\text { orientation }\end{array}$ & $\overline{\varepsilon_{\varphi=90 . \psi}}$ & $\begin{array}{l}\text { Zone- } \\
\text { oxis }\end{array}$ & $\begin{array}{l}\text { Phose } \\
\text { solid } \\
\text { solution }\end{array}$ & $\{n k \mid\}$ \\
\hline \multirow{2}{*}{211}$\langle 011\rangle$ & \multirow{2}{*}{$\begin{array}{l}\left(s_{12}+\frac{1}{6} s_{0}\right) \sigma_{1}+\left(s_{12}+\frac{1}{3} s_{0}\right) \sigma_{2} \cdot\left(s_{12}+\frac{1}{2} s_{44}+\frac{1}{2} s_{0}\right) \sigma_{3} \\
\cdot \frac{1}{2}\left[\frac{1}{3} s_{0} \sigma_{1}+s_{46} \sigma_{2}-\left(\frac{1}{3} s_{0}+s_{44}\right) \sigma_{3}\right] \sin ^{2} \Psi \\
+\frac{1}{6} \sqrt{2} s_{0}\left(\sigma_{1}-\sigma_{3}\right) \sin 2 \Psi\end{array}$} & \multirow{2}{*}{ [017] } & $\mathrm{Fe}$ & $\begin{array}{l}(110)\{200\}\{211\} \\
\{220\}\{222\}\end{array}$ \\
\hline & & & Cu $2 n$ & $\{211\}$ \\
\hline \multirow{2}{*}{$|011\rangle\langle 217\rangle$} & \multirow{2}{*}{$\begin{array}{l}\left(s_{12}+\frac{1}{6} s_{0}\right) \sigma_{1}+\left(s_{12}+\frac{1}{3} s_{0}\right) \sigma_{2}+\left(s_{12}+\frac{1}{2} s_{44}+\frac{1}{2} s_{0}\right) \sigma_{3} \\
\cdot \frac{1}{2}\left[\frac{1}{3} s_{0} \sigma_{1}+s_{44} \sigma_{2}-\left(\frac{1}{3} s_{0}+s_{44}\right) \sigma_{3}\right] \sin ^{2} \Psi\end{array}$} & \multirow{2}{*}{ [21i] } & $\mathrm{Ni}$ & \multirow{2}{*}{220}$\{(311\} \mid\{420\}$ \\
\hline & & & Cu & \\
\hline$\{111\}\langle 2 i \overline{1}\rangle$ & $\begin{array}{l}\left(s_{12}+\frac{1}{3} s_{0}\right) \sigma_{1}+\left(s_{12}+\frac{1}{3} s_{0}\right) \sigma_{2}+\left(s_{12}+\frac{1}{2} s_{44}+\frac{1}{3} s_{0}\right) \sigma_{3} \\
+\frac{1}{6}\left[-s_{0} \sigma_{1}+\left(3 s_{44}+s_{0}\right) \sigma_{2}-3 s_{44} \sigma_{3}\right] \sin ^{2} \Psi\end{array}$ & | 2191$]$ & $\mathrm{Fe}$ & $(110)(222\}$ \\
\hline$\{100\}\langle 011\rangle$ & $\begin{array}{l}s_{12} \sigma_{1} \cdot s_{12} \sigma_{2} \cdot s_{11} \sigma_{3} \\
+\frac{1}{2}\left[s_{0} \sigma_{1} \cdot\left(s_{44}+s_{0}\right) \sigma_{2}-\left(2 s_{0} \cdot s_{44}\right) \sigma_{3}\right] \sin ^{2} \Psi\end{array}$ & $|011|$ & $\mathrm{Fe}$ & $\begin{array}{l}\{110\}\{200\}\{211\} \\
\{222\}\end{array}$ \\
\hline \multirow{2}{*}{211}$\langle(111\rangle$ & \multirow{2}{*}{$\begin{array}{l}\left(s_{12}+\frac{1}{3} s_{0}\right) \sigma_{1}+\left(s_{12}+\frac{1}{6} s_{0}\right) \sigma_{2}+\left(s_{12}+\frac{1}{2} s_{44}+\frac{1}{2} s_{0}\right) \sigma_{3} \\
+\frac{1}{2}\left[\left(s_{46}+\frac{2}{3} s_{0}\right) \sigma_{2}-\left(\frac{2}{3} s_{0}+s_{44}\right) \sigma_{3}\right] \sin ^{2} \Psi\end{array}$} & \multirow{2}{*}{ [1111] } & $\mathrm{Ni}$ & \multirow{2}{*}{220}$(844)$ \\
\hline & & & Cu & \\
\hline
\end{tabular}

Figure 4 Formulae for strain stress relation of five ideal orientations, RD $(\varphi=0)$ and TD $(\varphi=90)$ (Hauk, 1986). 


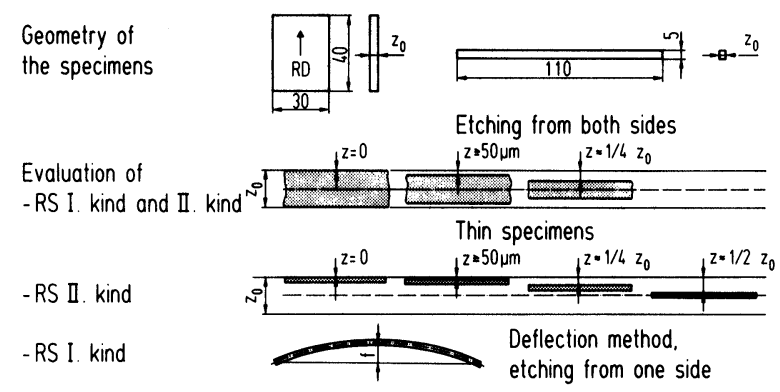

Figure 5 Evaluation of the distribution of RS I and RS II on strips and sheets for a symmetrical distribution of RS I.

The RS distributions over the depth can be determined if measurements are done after stepwise etching off surface layers (Hauk and Stuitje, 1985). The separation can be achieved also in quasi single phase materials, i.e. materials which can be measured only in one phase, if additional measurements are made on small very thin specimens which can be considered free of RS I (Hauk, 1983, 1984, 1987b). Only the use of neutrons having a large penetration depth because of their low attenuation factor allows a nondestructive determination of RS I and RS II over the cross-section. (Pintschovius et al., 1987). In all cases a mechanical method-for example the etching-deflection method-should be used to determine the distribution of RS I.

Figure 5 demonstrates in principle the method of the complete determination of the distributions of RS I and RS II on strips and sheets for a symmetrical RS I distribution. Two different sizes of specimens are used for the X-ray and mechanical investigations. It has to be checked whether the cutting of the specimens of different sizes leads to relaxation of RS by different amounts. In most cases it is sufficient to determine the sum of RS I + II as a function of depth after etching off surface layers. To determine the distribution of RS II it is necessary to make measurements on very thin specimens which are taken from different parts of the cross-section. It is obvious that thin specimens could have curved surfaces if there were RS I in the material. Besides it has to be considered that there also could be RS I in thin specimens. Therefore the thickness of these specimens should be chosen as thin as possible. Taking the 
results of the measurements on compact specimens after etching on both sides and the mentioned measurements on thin specimens taken from different parts of the cross-section the amounts and distributions of RS I and RS II can be determined. The results of the mechanical method can be used to check the X-ray results. On the other hand the mechanical method, etching-deflection method, is a simple and relatively fast method to determine the RS I distribution.

\section{MATERIAL AND EXPERIMENTS}

The investigations were done on an $88 \%$ cold rolled steel strip, $0.26 \mathrm{~mm}$ thick. Table 2 contains the data of the chemical composition and of the strength. Figure 6 shows the microstructure. Figure 7 shows for example the intensity polefigure of $\{110\}$ and the ODF for a specimen after etching off $50 \mu \mathrm{m}$. Additional measurements of the texture on the surface and the above mentioned tests after electrolytic etching off a $50 \mu \mathrm{m}$ thick surface layer have the following result. There exists a typical rolling texture which does not alter with depth from the surface and which can be approximately described by the three ideal orientations $\{211\}\langle 01 \overline{1}\rangle$, $\{111\}\langle 2 \overline{1} \overline{1}\rangle$ and $\{100\}\langle 011\rangle$ (Wassermann and Grewen, 1962). In case of measuring on the $\{111\}\langle 2 \overline{1} \overline{1}\rangle$ crystallite group the evaluation of the ODF shows that superimpositions with other crystallite groups must be expected.

The X-ray measurements were carried out on four specimens

Table 2 Data of the chemical composition (in weight \%) and of the strength

\begin{tabular}{llllllll}
\hline $\mathrm{C}$ & $\mathrm{Si}$ & $\mathrm{Mn}$ & $\mathrm{P}$ & $\mathrm{S}$ & $\mathrm{Cu}$ & $\mathrm{Al}$ & $\mathrm{N}_{2}$ \\
\hline 0.076 & 0.044 & 0.51 & 0.013 & 0.015 & 0.03 & 0.051 & 0.0053 \\
\hline
\end{tabular}

\begin{tabular}{lllll}
\hline $\begin{array}{l}R_{p 0.2} \\
\mathrm{MPa}\end{array}$ & $\begin{array}{l}R_{m} \\
\mathrm{MPa}\end{array}$ & $\begin{array}{c}A_{g} \\
\%\end{array}$ & $\begin{array}{c}A \\
\%\end{array}$ & HR 30T \\
\hline 920 & 1015 & 1.0 & 1.2 & 82 \\
\hline
\end{tabular}




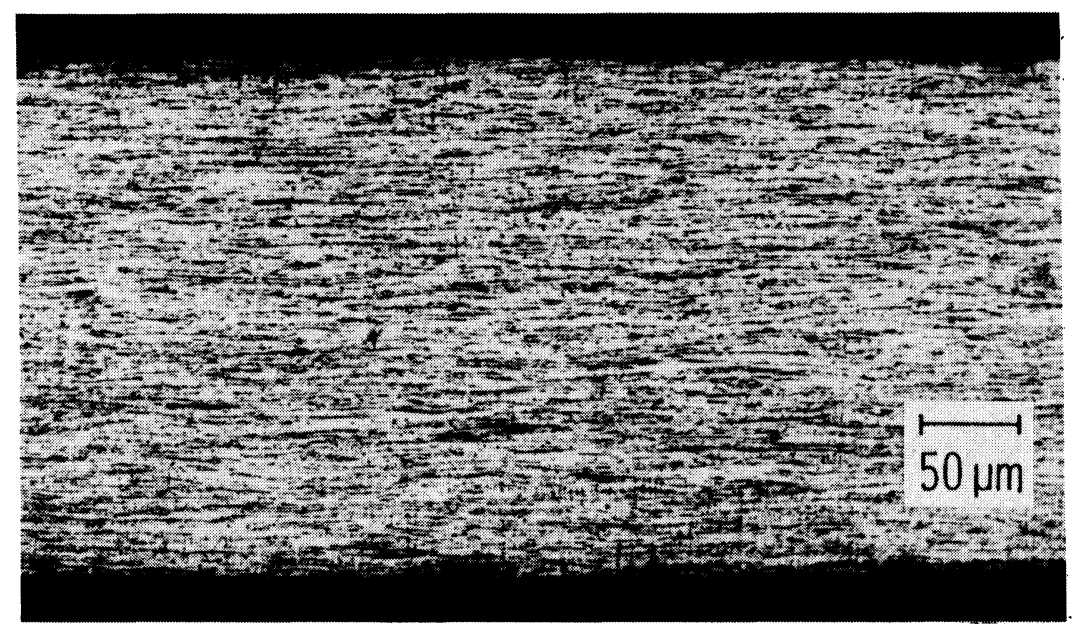

Figure 6 Microstructure of the strip tested, RD, etching with $\mathrm{HNO}_{3}, 10$ s.

sized $40 \times 30 \mathrm{~mm}^{2}$ taken from a strip of dimensions $500 \times 300 \mathrm{~mm}^{2}$, Figure $8 . \mathrm{HNO}_{3}$ was used as an etching liquid. For the lattice strain measurements by $\mathrm{X}$-rays in $\mathrm{RD}$ and TD the following radiations and peaks were used: $\mathrm{Cr}-\mathrm{K}_{\alpha}-\{211\}$ and $\{200\}, \mathrm{Fe}-\mathrm{K}_{\alpha}-\{220\}$, $\mathrm{Cu}-\mathrm{K}_{\alpha}-\{222\}$ and $\mathrm{Mo}-\mathrm{K}_{\alpha}-\{732+651\}$. Figure 8 shows on which surfaces of the specimens the measurements were taken and which radiations were used. Two computer controlled $\Psi$-diffractometers were employed. The peaks of the $\mathrm{K}_{\alpha 1}-\mathrm{K}_{\alpha 2}$-doublets were registered using a single slit and the doublets were separated or the peaks were symmetrized by computer after the backgound had been subtracted (Hauk and Krug, 1983). To determine the exact peak position the method of the centre of gravity was used with variation of the lower intensity threshold from 0.55 to 0.8 of the maximum intensity. In all cases other than measurements with $\mathrm{Cr}$-radiation, a $\beta$-filter was used. Measurements were taken in the range $-71.6^{\circ} \leqq \psi \leqq 71.6^{\circ}$ except of measurements on the $\{200\}$-peak at $\psi=0^{\circ}$ using Crradiation. The calibration of both $\Psi$-diffractometers was done using stress free tempered $\mathrm{Au}$ and $\mathrm{Fe}$ powders so that the peak position was independent of $\psi$ within $\pm 0.01^{\circ}$ in $2 \theta$. For the mechanical tests of the RS I determination two specimens of size $110 \times 5 \mathrm{~mm}^{2}$ were taken in RD and TD. The etching with $\mathrm{HNO}_{3}$ was done in steps of 

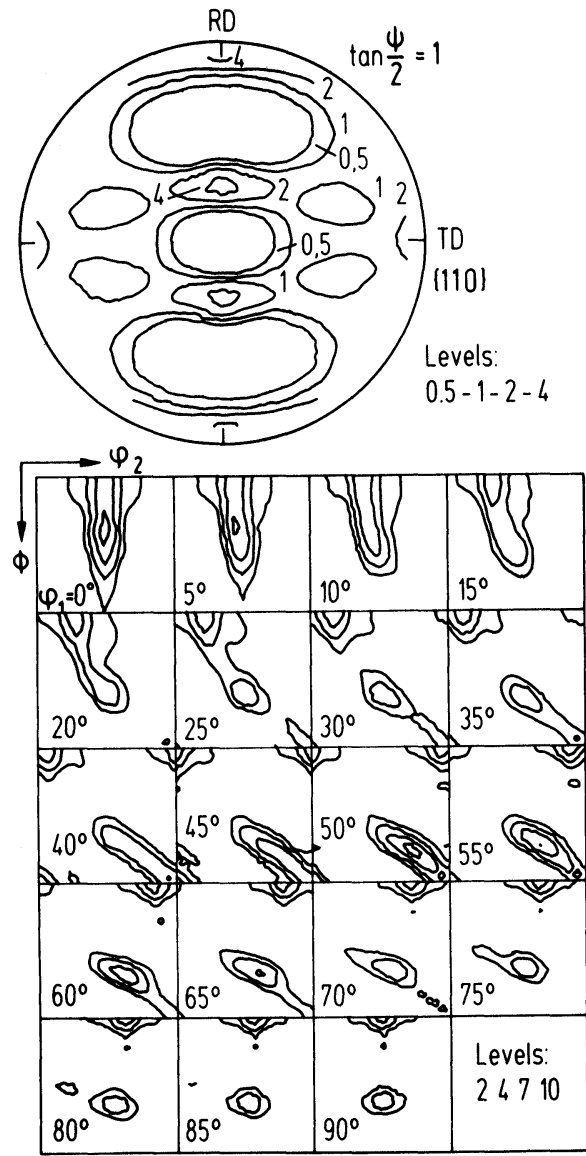

Figure 7 Intensity polefigure of the $\{110\}$ peak and ODF for a specimen after etching off $50 \mu \mathrm{m}$.

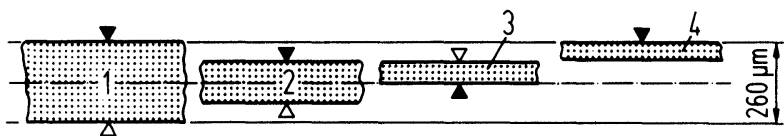

Figure 8 Position of the specimens and selection of surfaces and radiations for the measurements. $\nabla$ Measurements with $\mathrm{Cr}$-, $\mathrm{Fe}, \mathrm{Cu}$-, and Mo-radiation on the $\{211\}$-, $\{200\}-,\{220\}-,\{222\}-$ and $\{732+651\}$-peaks. $\nabla$ Measurements with Cr-radiation on the $\{211\}$ peak. 
10-40 $\mu \mathrm{m}$ on the front side and on the back side. The deflection was measured after each etching step. From the measured deflections the RS I were calculated according to Treuting and Read (1951).

\section{RESULTS AND DISCUSSION}

\section{RS on the strip surface}

In Figures 9 and 10 the distributions of $D$ vs. $\sin ^{2} \psi$ and intensity vs. $\sin ^{2} \psi$ are drawn for the peaks $\{211\},\{220\},\{222\}$ and $\{732+651\}$, for $\mathrm{RD}$ and $\mathrm{TD}$, determined on the surface of specimen 1. For

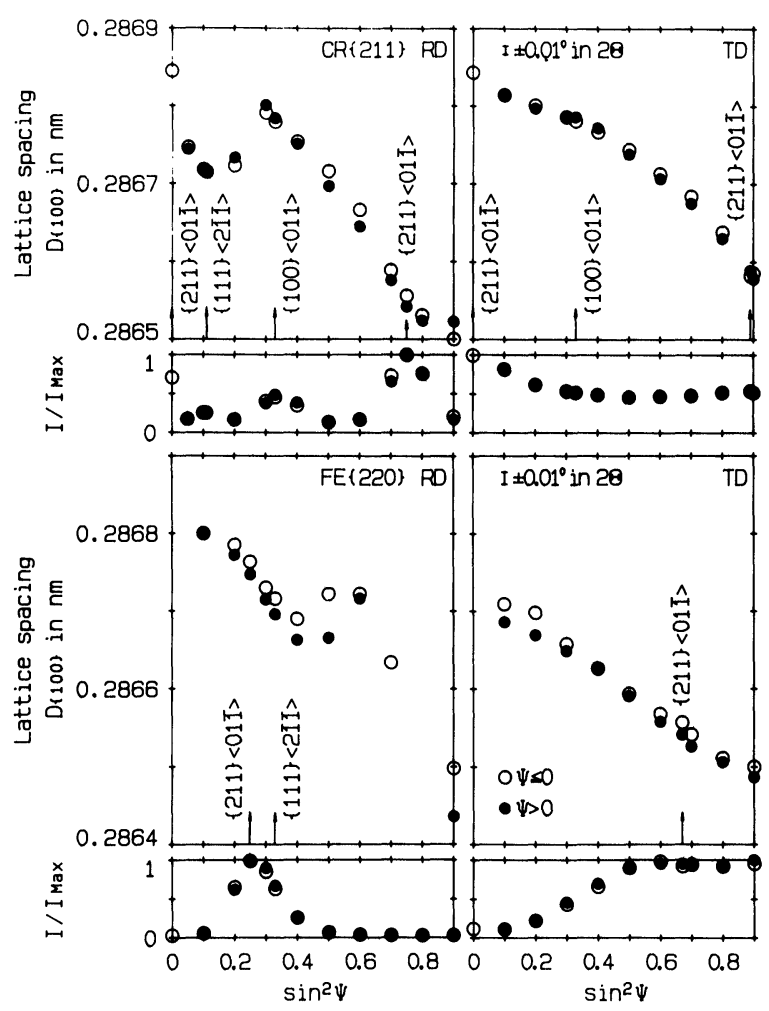

Figure 9 Distributions of D vs. $\sin ^{2} \psi$ and intensity vs. $\sin ^{2} \psi$ for the peaks $\{211\}$ and $\{220\}$ in RD and TD, specimen 1 . 


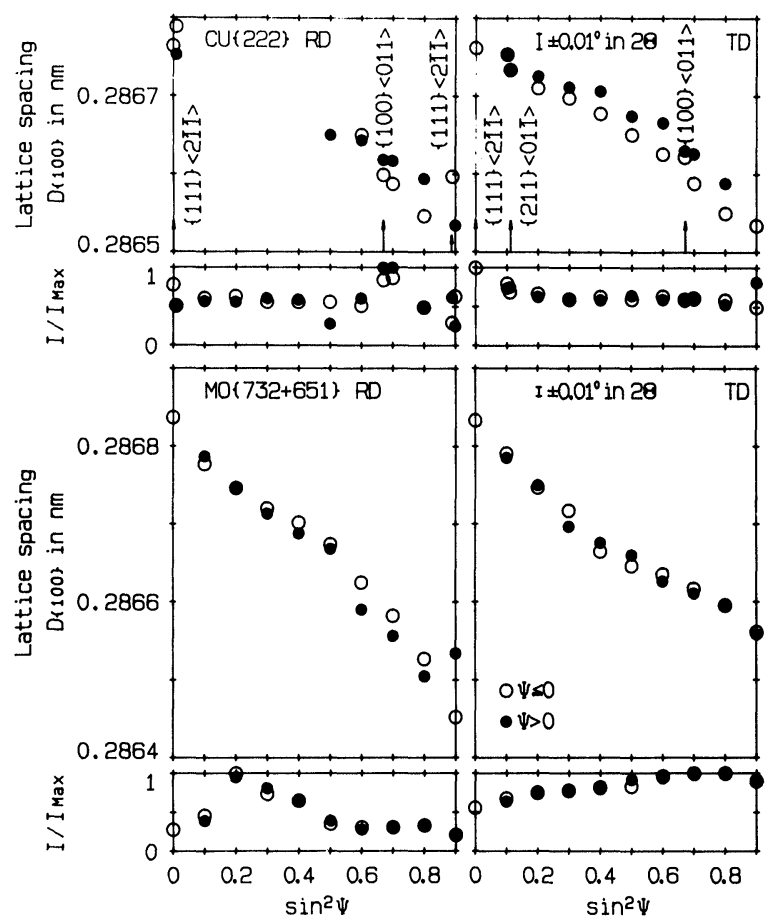

Figure 10 Distributions of D vs. $\sin ^{2} \psi$ and intensity vs. $\sin ^{2} \psi$ for the peaks $\{222\}$ and $\{732+651\}$ in RD and TD, specimen 1 .

comparison of the results obtained from different reflections the measured lattice spacings $\mathrm{D}_{\{h k l\}}$ were converted to $\mathrm{D}_{\{100\}}$. An error bar of $\pm 0.01^{\circ}$ in $2 \theta$ demonstrating the accuracy of calibration is drawn which allows the accuracy of the measurement to be estimated. There are some void areas which mean that the peak position could not be determined with the necessary accuracy because of low intensity. The $D$ vs. $\sin ^{2} \psi$ distributions of the $\{211\}$ peak show the typical non-linearity for cold rolled iron and steel. In contrast to that the $\{732+651\}$ peaks reveal linearity in RD and TD. The distributions of the intensity show the position of the poles of the indicated ideal orientations in most cases. The lattice constant $D_{0}$ of the stress free state was determined by using filings. The result was $0.286658 \mathrm{~nm}$. 


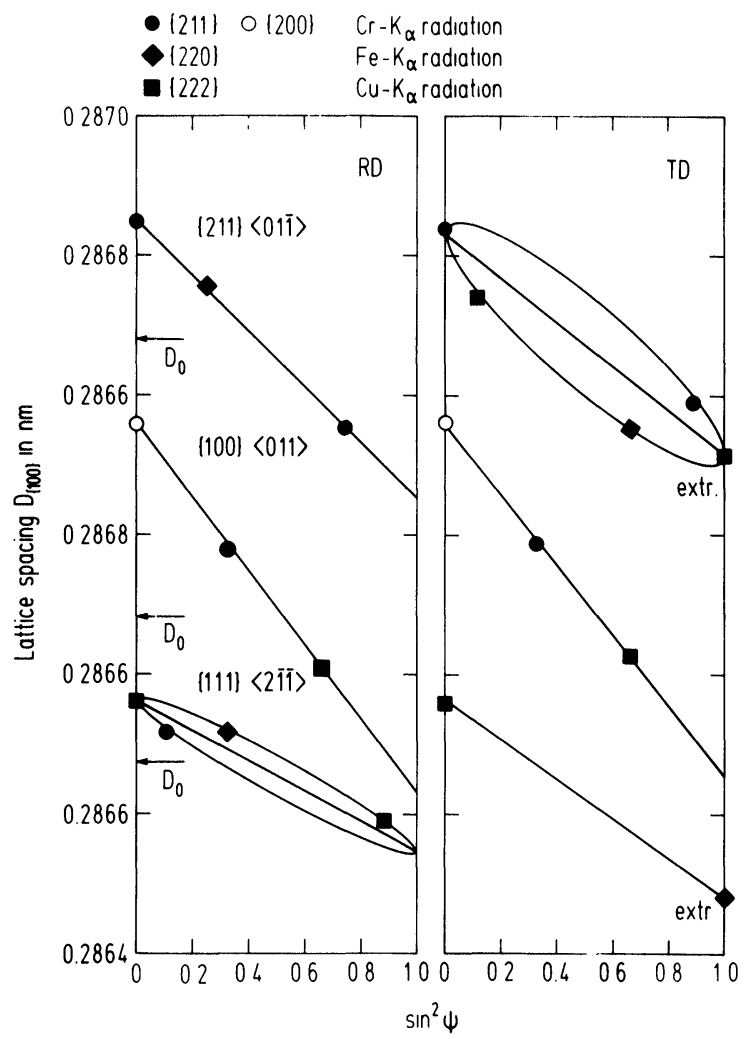

Figure 11 Lattice distances of different planes $\{h k l\}$ vs. $\sin ^{2} \psi$ taken from Figures 9 and 10 for the three crystallite groups, RD and TD, specimen 1, extr. determined by extrapolation.

The RS state on the surface was evaluated by using the crystallite group method. In Figure 11 the lattice distances of the different planes $\{h k l\}$ taken from the Figures 9 and 10 for each of the three ideal orientations are drawn for RD and TD. The two D-values at $\sin ^{2} \psi=1$ were determined by extrapolation. As Figure 11 shows, the measured results can be fitted by a linear or an elliptic dependency. The deviations from the expected lines are small. To calculate the RS the equations in Figure 4 and the compliances of the single crystal according to Landolt Börnstein (1979) were used. The RS of the crystallite groups are compiled in Table 3. These 
Table 3 RS (in MPa) evaluated by the crystallite group method and by linear regression analysis of the D vs. $\sin ^{2} \psi$ distributions, specimen 1

\begin{tabular}{cccccccc}
\hline & \multicolumn{5}{c}{ crystallite group method } & \multicolumn{5}{c}{ linear regression analysis } \\
\hline & $\{211\}\langle 01 \overline{1}\rangle$ & $\{100\}\langle 011\rangle$ & $\{111\}\langle 2 \overline{1} \overline{1}\rangle$ & $\mathrm{Cr}\{211\}$ & $\mathrm{Fe}\{220\}$ & $\mathrm{Cu}\{222\}$ & $\mathrm{Mo}\{732+651\}$ \\
\hline$\sigma_{1}-\sigma_{3}$ & -218 & -183 & -185 & $-182 \pm 21$ & $-213 \pm 26$ & $-162 \pm 13$ & $-216 \pm 10$ \\
\hline$\sigma_{2}-\sigma_{3}$ & -211 & -162 & -221 & $-176 \pm 8$ & $-166 \pm 5$ & $-161 \pm 10$ & $-161 \pm 7$ \\
\hline$\sigma_{3}$ & 36 & 41 & 24 & & & & \\
\hline
\end{tabular}

results are compared with the values of RS obtained by linear regression of the D vs. $\sin ^{2} \psi$ distributions using the XEC of a mechanically isotropic polycrystalline material (Bollenrath et al., 1967; Hauk and Macherauch, 1982). In contrast to the expectation all data show good agreement within certain limits. It should be emphasized that there is no physical argument for the used linear regression. The linearity of the $\mathrm{D}$ vs. $\sin ^{2} \psi$ distributions as a result of measurements with Mo-radiation on the $\{732+651\}$ peaks has the character of an averaging method because many orientations of the crystallites contribute to the peaks.

\section{Distribution of RS I and RS II over the cross-section}

The determination of the RSI and RS II with depth from the surface was done according to Figure 5 . On the surface of the specimens 2 and 3 the same measurements were performed as on specimen 1, Figure 8. For example Figures 12 and 13 show the distributions of the lattice spacings and the intensities vs. $\sin ^{2} \psi$ of the $\{211\}$ and $\{732+651\}$ peaks in RD and TD for two different depths from the surface. The distributions of the intensities show no significant alterations in comparison with Figures 9 and 10. The D vs. $\sin ^{2} \psi$ distributions of the $\{211\}$-peak show additional oscillations in RD. The D vs. $\sin ^{2} \psi$ dependencies of the $\{732+651\}$ peaks are no more linear.

It was checked by additional measurements on the other surfaces of the specimens 1 and 2 with Cr-radiation on the $\{211\}$ peak, 


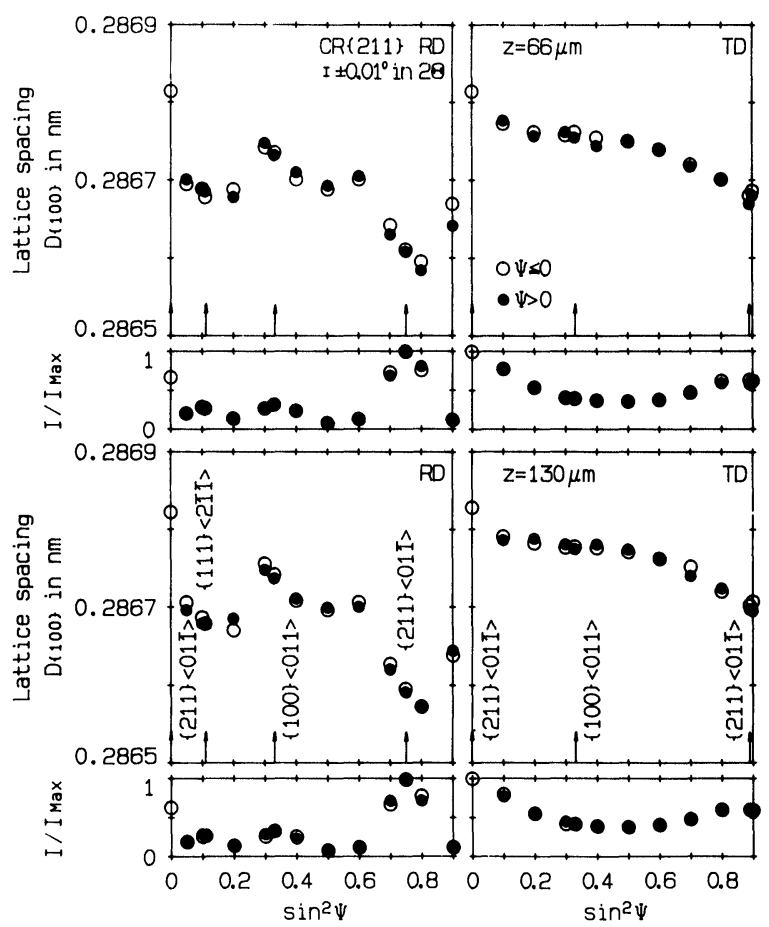

Figure 12 Distrioutions of D vs. $\sin ^{2} \psi$ and intensity vs. $\sin ^{2} \psi$ for the $\{211\}$ peak in $\mathrm{RD}$ and TD for two different depths $z$, specimens 2 and 3 .

Figure 8, whether the RS distributions are symmetrical. The D vs. $\sin ^{2} \psi$ distributions are the same within the measuring accuracy. Measurements with Cr-radiation on the specimens of both sizes reveal that there is no difference in the relaxation of RS because of the different sizes of the specimens for X-ray and mechanical investigations. The mechanical RS tests prove that there are no RS I in RD and in TD within an error of $\pm 15 \mathrm{MPa}$. To check the result that there are no RS I within the cold rolled strip additional measurements were made on a thin specimen, No 4, Figure 8 . The specimen No 4 was produced by etching the strip from one side down to a thickness of $50 \mu \mathrm{m}$. It can be expected that a specimen of a thickness of only $50 \mu \mathrm{m}$ is free of RS I. All the results of D vs. $\sin ^{2} \psi$ measurements on $\{211\},\{220\},\{222\}$ and $\{732+651\}$ 


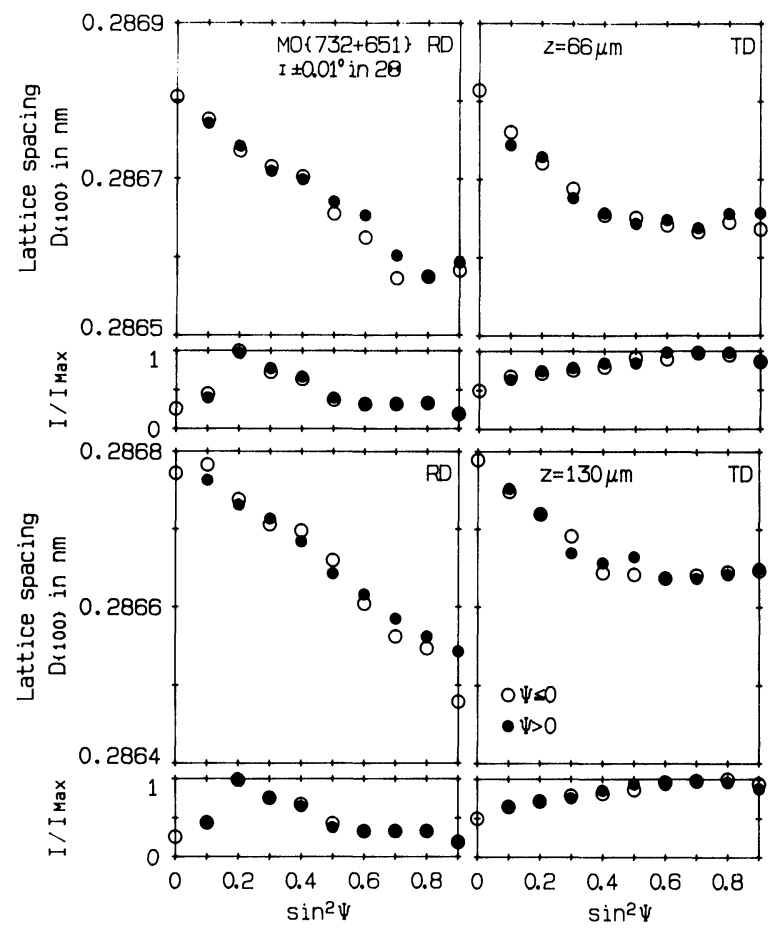

Figure 13 Distributions of D vs. $\sin ^{2} \psi$ and intensity vs. $\sin ^{2} \psi$ for the $\{732+651\}$ peaks in RD and TD for two different depths $z$, specimen 2 and 3.

reflections are the same as on the surface of specimen 1. For example the distributions of lattice spacing and intensity vs. $\sin ^{2} \psi$ of the $\{211\}$ and the $\{732+651\}$ peaks are shown in Figure 14. The comparison with the distributions shown in Figures 9 and 10 exhibits no differences. The same result was obtained for specimens 2 and 3 , Figure 8 , as the measurements with Cr-radiation show. The manifold results lead to the conclusion that the investigated steel strip only is in the state of RS II.

The determination of RS in the different depths from the surface was done in the same manner as on the surface of the specimen 1. The RS $\sigma_{1}-\sigma_{3}$ and $\sigma_{2}-\sigma_{3}$ which have been evaluated according to the preferred oriented crystallite group method have been drawn in Figure 15 related to the three crystallite groups as a function of the 


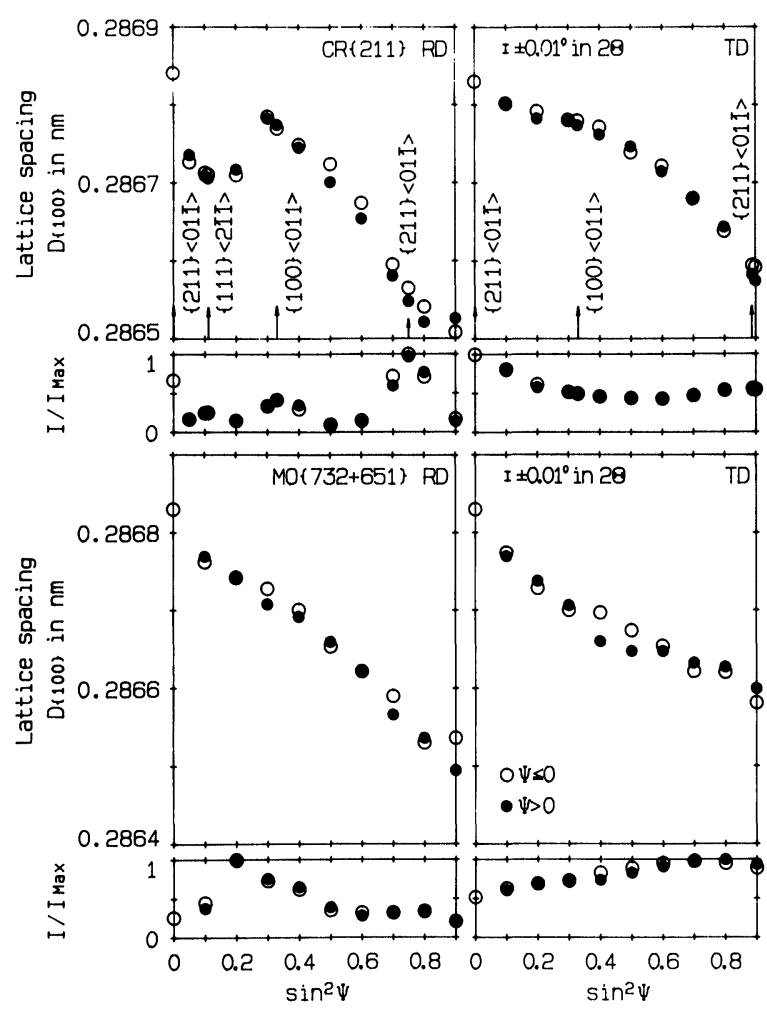

Figure 14 Distributions of D vs. $\sin ^{2} \psi$ and intensity vs. $\sin ^{2} \psi$ for the peaks $\{211\}$ and $\{732+651\}$ in RD and TD, specimen 4 .

depth. The agreement between the results gained on the specimens 1 and 4 for the crystallite groups demonstrates again that RS II are present. The RS in RD show agreement for all three crystallite groups on the strip surface but there are differences in different depths from the surface. The decrease of the compression RS II with the depth from the surface is small for the values of the $\{211\}\langle 01 \overline{1}\rangle$ and $\{100\}\langle 011\rangle$ and is large, approximately $160 \mathrm{MPa}$, for the $\{111\}\langle 2 \overline{1} \overline{1}\rangle$ crystallite group, an explanation may be the above mentioned superimpositions of several ideal orientations. In contrast, the compression RS II of all three crystallite groups decreases in TD in the same manner. 


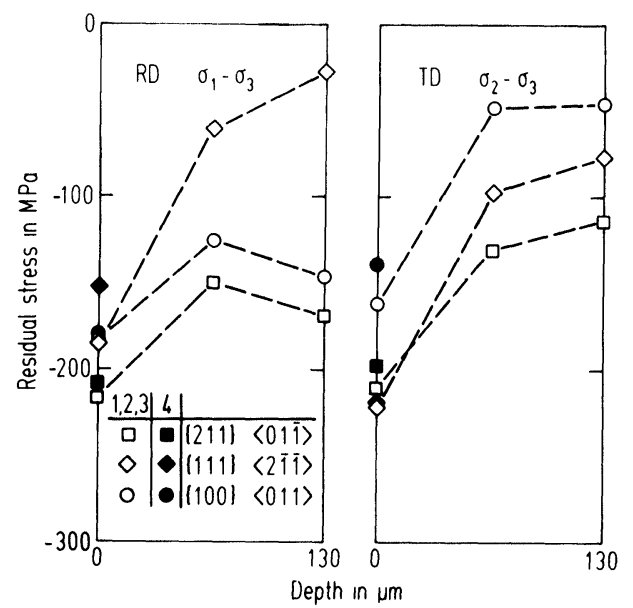

Figure 15 RS vs. depth evaluated according to the crystallite group method.

The determination of the RS components in the thickness direction $\sigma_{3}$ requires a knowledge of the exact interplanar spacing of the stress free state $\mathrm{D}_{0}$. The values of $\sigma_{3}$ shown in Figure 16 were determined using the equations in Figure 4 with the value $D_{0}=$ $0.286658 \mathrm{~nm}$ as measured on filings. Additionally Figure 16 shows the variation of $\mathrm{D}_{0}$ calculated with the assumption $\sigma_{3}=0$. The values so determined have a total difference of $4 \cdot 10^{-5} \mathrm{~nm}$ and the

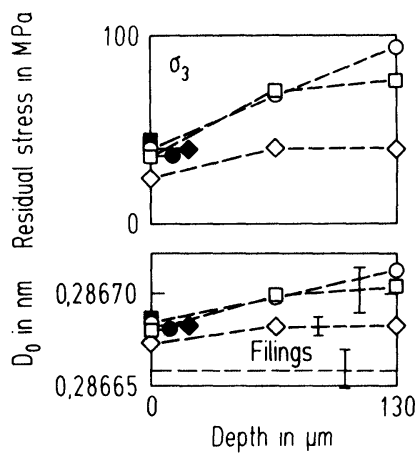

Figure $16 \mathrm{RS}$ component in thickness direction $\sigma_{3}\left(\mathrm{D}_{0}=0.286658 \mathrm{~nm}\right)$ and interplaner spacing of the stress free state $\mathrm{D}_{0}\left(\sigma_{3}=0\right)$ both vs. depth; symbols see Figure 15. 


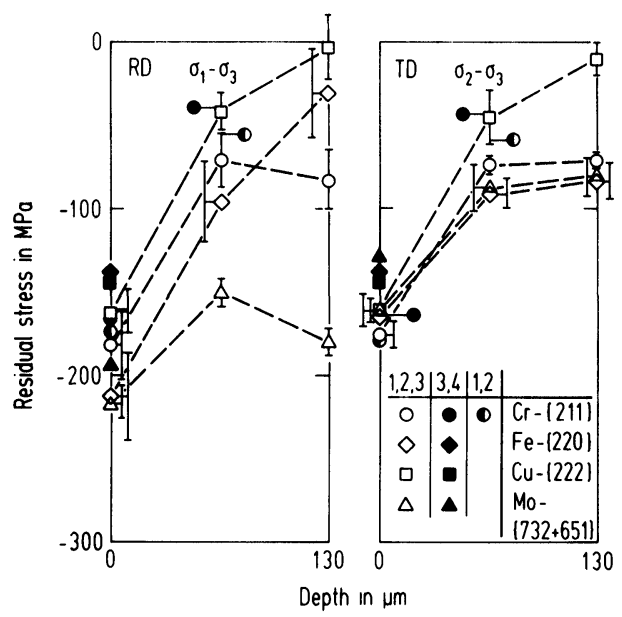

Figure 17 RS vs. depth evaluated by linear regression analysis of the D vs $\sin ^{2} \psi$ distribution.

mean value differs from the value measured on filings by $3 \cdot 10^{-5} \mathrm{~nm}$. Recognizing the errors of measurement and determination the conclusion will be taken that the variation of $\mathrm{D}_{0}$ and $\sigma_{3}$ with the depth is not significant. The question whether there exists a difference between the mean value and the value measured on filings which may be influenced by the RS II is still open, but any such difference is in the range of the measuring accuracy.

Figure 17 shows the variation of the RS with depth from the surface of the values obtained by linear regression analysis of the $\mathrm{D}$ vs. $\sin ^{2} \psi$ distributions. The error bars characterize the accuracy of the results. The variation of the so determined RS with depth shows qualitative agreement with the variation shown in Figure 15. Although the method of linear regression seems to be very common to evaluate RS on textured materials, this method should be employed only after careful checking and calibration by another method.

As a new aspect is should be recognized that the D vs. $\sin ^{2} \psi$ distributions of the $\{732+651\}$ reflections in TD are no longer linear below the surface, so that a linear regression is no longer applicable. The evaluation of the RS state on this steel strip, low alloyed steel, high cold rolling reduction, small thickness of the strip proves that only RS II are present. A statement that RS determined 
by linear regression of the $\mathrm{D}$ vs. $\sin ^{2} \psi$ distributions on the $\{732+651\}$ peaks are of the I. kind (Maurer et al., 1987) should be thoroughly checked by measurements on small thin specimens and/or by the etching-deflection method.

The crystallite group method has proven useful to evaluate RS in materials having strongly preferred orientations. Summarizing the results of the crystallite group method and averaging the values of the three crystallite groups show the following: On the surface of the strip there are compression RS in RD and in TD of approximately $-200 \mathrm{MPa}$. They decrease to the center of the strip in RD to $-110 \mathrm{MPa}$ and in TD to $-80 \mathrm{MPa}$. The RS variation in the first layers could be verified in more detail but there is agreement with similar results on textured nickel concerning the variation of RS II (Hauk and Oudelhoven, 1988). The differences of the RS II within the crystallite groups increase in the RD with depth from the surface, the alterations in TD are small. At present there is only the explanation that the compensation of the RS II takes place in those regions which do not contribute to the diffraction intensity, i.e., at the neighborhood of grain boundaries and/or grains of additional phases (Hauk, 1982b). Nevertheless the existence of these RS II is out of the question and it seems to be very interesting to investigate their importance with regard to load of materials. It is valuable to mention that the variation of RS and RD of the $\{732+651\}$ peaks is the same as the mean value for two crystallite groups, Figure 15 and 17.

With the aid of ODF texture and RS state of the material will be better understood if the results of additional crystallite groups are considered (Pintschovius et al., 1987). It is hoped to obtain a better understanding of the states of RS in the different oriented crystallite groups and their coupling and to calculate the mean value of RS within the material taking into account the volume content of each crystallite group.

\section{CONCLUSION}

To summarize, the following items are stated and the following procedure recommended: 
- X-ray and neutron diffraction methods determine the sum RS I + II (macro- and micro- RS).

- Lattice planes with high indices, also multiple reflections may show linear D vs. $\sin ^{2} \psi$ dependencies.

- The separation of the different amounts of RS I and of RS II can be achieved by additional X-ray measurements on small thin specimens (no RS I) and/or by mechanical methods (only RS I) using for example the etching-deflection method.

- A linear regression of the D vs. $\sin ^{2} \psi$ results $(\psi, \Delta \psi$ small, $\sin ^{2} \psi \leqq 0.9$ ) may give useful values of RS, although there exists no physical justification for that procedure.

- RS I, RS II and texture may have gradients with the depth from the surface.

- The statements on the linearity of the D vs. $\sin ^{2} \psi$ dependency, on the existence of the amounts of RS I and of RS II including their gradients should be verified very carefully by accurately determining the absolute interplanar spacing in different depths from the surface and on different peaks.

- The existence of $\sigma_{3}-$ or $\mathrm{D}_{0}$-gradients should be checked by additional physical and mechanical methods.

- The results of measurement and evaluation on a cold rolled steel strip demonstrate the recommended procedure.

- Further developments of the crystallite group method are indicated.

\section{Acknowledgment}

The authors would like to thank the Deutsche Forschungsgemeinschaft for financial support, the Rasselstein company for the material, the chemical composition- and the strength-data and the Institut für Metallkunde, Prof. Dr. K. Lücke, for the texture analysis.

\section{References}

van Baal, C. M. (1983) phys. stat. sol (a) 77, 521-526.

Baron, H. U., Hauk, V., Oudelhoven, R. W. M. and Weber, B. (1987) In: Residual Stresses in Science and Technology, Eds, E. Macherauch and V. Hauk, DGM Informationsgesellschaft Verlag, Oberursel Vol 1, 409-416. 
Baron, H. U. and Hauk, V. (1988). Z. Metallkde., 79, 127-131.

Barral, M., Sprauel, J. M. and Maeder, G. (1983). In: Eigenspannungen, Eds. E. Macherauch and V. Hauk, DGM Oberursel, Vol 2, 31-47.

Barral, M., Lebrun, J. L., Sprauel, J. M. and Maeder, G. (1984). Proc. 7th Intern. Conf. on Textures of Materials, ICOTOM 7 Sept 17-21, Noordwijkerhout, The Netherlands, 555-560.

Bollenrath, F., Hauk, V. and Müller, E. H. (1967) Z. Metallkde 58, 76-82.

Brakman, C. M. (1983). J. Appl. Cryst. 16, 325-340.

Brakman, C. M. and Penning, P. (1984) Proc. 7th Intern. Conf. on Textures of Materials, ICOTOM 7 Sept 17-21, Noordwijkerhout, The Netherlands, 561566.

Brakman, C. M. (1985). Cryst. Res. Technol. 20, 593-618.

Bunge, H. J. (1965). Z. Metallkde 56, 872-874.

Dölle, H. and Hauk, V. (1978). Z. Metallkde 69, 410-417.

Dölle, H. and Hauk, V. (1979). Z. Metallkde 70, 682-685.

Feja, K., Hauk, V., Krug, W. K. and Pintschovius, L. (1987). Mat. Sci. and Eng. 92,13-21.

Glocker, R. (1938). Z. tech. Phys. 19, 289-293.

Hauk, V. (1955). Arch f. d. Eisenhüttenwes. 26, 275-278.

Hauk, V. Herlach, D. and Sesemann, H., (1975). Z. Metallkde 66, 734-737.

Hauk, V. and Sesemann, H. (1976). Z. Metallkde 67, 646-650.

Hauk, V. and Kockelmann, H. (1978). Z. Metallkde 69, 16-21.

Hauk, V. (1982a). In: Eigenspannungen und Lastspannungen, Eds. V. Hauk and E. Macherauch, Carl Hanser Verlag, München Wien, 49-57.

Hauk, V. (1982b). In: Eigenspannungen und Lastpannungen, Eds. V. Hauk and E. Macherauch, Carl Hanser Verlag, München Wien, 92-100.

Hauk, V. and Macherauch, E. (1982). In: Eigenspannungen und Lastspannungen, Eds. V. Hauk and E. Macherauch, Carl Hanser Verlag, München Wien, 1-19.

Hauk, V. In: Eigenspannungen, Eds. E. Macherauch and V. Hauk, DGM Oberursel, Vol 1, 9-48 (1983) in German; DGM Oberursel, 9-45 (1986) in English.

Hauk, V. and Krug, W. K. (1983). Materialprüf. 25, 241-243.

Hauk, V. and Vaessen, G. In: Eigenspannungen, Eds. E. Macherauch and V. Hauk, DGM Oberursel, Vol 2, 9-30 (1983) in German; DGM Oberursel 231-245 (1986) in English.

Hauk, V. (1984). Adv. X-ray Anal. 27, 101-120.

Hauk, V. and Macherauch, E. (1984). Adv. X-ray Anal. 27, 81-99.

Hauk, V. and Stuitje, P. T. J. (1985). Z. Metallkde 76, 445-451 and 471-474.

Hauk, V. and Vaessen, G. (1985). Z. Metallkde 76, 102-107.

Hauk, V., Vaessen, G. and Weber, B. (1985). Härterei-Tech. Mitt. 40, 122-128.

Hauk, V. M. (1986). Adv. X-ray Anal. 29, 1-15.

Hauk, V. (1987a). In: Advances in Surface Treatment, Ed. A Niku-Lari, Pergamon Press Vol 4, 251-302.

Hauk, V. (1987b). In: Residual Stresses in Science and Technology, Eds E. Macherauch and V. Hauk, DGM Informationsgesellschaft Verlag, Oberursel Vol 1, 353-360.

Hauk, V., Krug, W. K., Oudelhoven, R. W. M. and Pinschovius, L. (1988). Z. Metallkde, 79, 159-163.

Hauk, V. and Oudelhoven, R. W. M. (1988). Z. Metallkde, 79, 41-49.

Honda, K., Hosokawa, N. and Sarai, T. (1978). J. Soc. Mater. Sci Japan 27, 278-284.

Kloos, K. H. (1979). Z. Werkstofftechn. 10, 293-302. 
Landolt Börnstein, (1979). New Series, Group III, Vol 11, Springer-Verlag, Berlin-Heidelberg-New York.

Macherauch, E., Wohlfahrt, H. and Wolfstieg, U. (1973). Härterei-Tech. Mitt 28, 201-211.

Maurer, G., Neff, H., Scholtes, B. and Macherauch, E. (1987). Z. Metallkde 78, $1-7$.

Möller, H. and Martin, G. (1939). Mitt. Kaiser-Wilhelm-Inst. Eisenforsch., Düsseldorf, 21, 261-269.

Pintschovius, L., Hauk, V. Krug, W. K. (1987). Mat. Sci. and Eng. 92, 1-12.

Reuss, A. Z. (1929). Z. Angew. Math. Mech. 9, 49-58.

Roe, R. J. (1965). J. Appl. Phys. 36, 2024-2031.

Schiebold, E. (1938). Berg- und Hüttenm. Monatsh. 86, 278-295.

Serruys, W., van Houtte, P. and Aernoudt, E. (1987). In: Residual Stresses in Science and Technology, Eds. E. Macherauch and V. Hauk, DGM Informationsgesellschaft Verlag, Oberursel Vol 1, 417-424.

Shiraiwa, T. and Sakamoto, Y. (1970). Proc 13th Jap. Congr. on Mater. Res.-Metal. Mater., 25-32.

Taira, S., Hayashi, K. and Watase, Z. (1969). Proc 12th Jap. Congr. Mater. Res., Kyoto, 1-7.

Treuting, R. G. and Read, W. T. (1951). J. Appl. Phys. 22, 130-134.

Voigt, W., (1928). Lehrbuch der Kristallphysik, Leipzig-Berlin.

Wassermann, G. and Grewen, J. (1962). Texturen metallischer Werkstoffe, 2. Ed., Springer-Verlag, Berlin-Göttingen-Heidelberg.

Willemse, P. F., Naughthon, B. P. and Verbraak, C. A. (1982). Mat. Sci. and Eng. 56, 25-37.

Willemse, P. F. and Naughthon, B. P. (1985). Mater. Sci. and Technol. 1, 41-44.

Wolfstieg, U. and Macherauch, E. (1976). Härterei-Tech. Mitt. 31, 2-3. 